\title{
ADUBAÇÃO DE PORTA-ENXERTOS DE SERINGUEIRA EM VIVEIRO SUSPENSO
}

\author{
Rafael Ferreira Barreto ${ }^{1 *}$, Wilson Itamar Maruyama ${ }^{2}$, Diógenes Martins Bardiviesso ${ }^{2}$, Tiago da Silva Rodrigues ${ }^{3}$, \\ Eric Fabiano Seraguzi ${ }^{1}$, Ale xandre Vendrame Barbosa ${ }^{3}$ \\ ${ }^{1}$ Universidade Federal de Mato Grosso do Sul, Programa de Pós-Graduação em Agronomia, Chapadão do Sul, Mato Grosso do Sul, Brasil - \\ *rafael.fb@outlook.com; eric_seraguzi@hotmail.com \\ ${ }^{2}$ Universidade Estadual de Mato Grosso do Sul, Departamento de Agronomia, Cassilândia, Mato Grosso do Sul, Brasil - \\ wilsonmaruyama@hotmail.com; bardiviesso@yahoo.com.br \\ ${ }^{3}$ Universidade Estadual de Mato Grosso do Sul, Curso de Agronomia, Cassilândia, Mato Grosso do Sul, Brasil - tiago_agro13@hotmail.com; \\ alexandreavb@hotmail.com
}

Recebido para publicação: 15/10/2013 - Aceito para publicação: 11/11/2015

\begin{abstract}
Resumo
A produção de porta-enxertos de seringueira em viveiro suspenso evita a contaminação por patógenos de solo, porém existem poucas informações sobre adubação nesse sistema. Objetivou-se verificar a influência de diferentes concentrações de nitrogênio, fósforo e potássio, em solução nutritiva, sobre o crescimento de portaenxertos de seringueira em viveiro suspenso. Tratamentos: 0, 35, 70, 105 e $140 \mathrm{mg} \cdot \mathrm{planta}^{-1} \cdot \mathrm{semana}^{-1}$, conduzidos num delineamento em blocos casualizados, totalizando 4 repetições. As aplicações foram realizadas de outubro de 2012 a janeiro de 2013. A parcela foi constituída por 10 porta-enxertos de seringu eira (clone desconhecido), sustentados no viveiro suspenso por garrafas PET. Aos 30, 45, 60, 75 e 90 dias após a aplicação, foram avaliados: diâmetro do caule, altura de plantas, número de folíolos e índice de cor verde. Aos 100 dias após a aplicação, realizou-se a avaliação final, por meio da massa seca, área foliar e índices fisiológicos. A dose de $140 \mathrm{mg}$.planta ${ }^{-1}$ via fertirrigação é a mais adequada para a produção de portaenxertos em viveiro suspenso. Contudo, o potencial máximo de crescimento das plantas não foi atingido com as doses testadas. Para a obtenção de resultados satisfatórios, é recomendado o uso de sementes de portaenxertos de seringueira de alta qualidade.

Palavras-chave: Hevea brasiliensis; produção de mudas; solução nutritiva.
\end{abstract}

\section{Abstract}

Fertilization of rootstocks of rubber tree in nursery suspended. The production of rootstocks in nurseries rubber tree suspended prevents contamination by soil pathogens, however, little information exists about system this fertilization. This study aimed to determine the dosage of nitrogen, phosphorus and potassium in nutrient solution, over growth rubber tree rootstocks. The following concentrations were adopted: $0,35,70$, 105 and $140 \mathrm{mg} \mathrm{plant}^{-1}$ week $^{-1}$. The experimental design was randomized blocks, with 4 repetitions. Fertilizers were applied since October 2012 into January 2013. The plot consisted of 10 rootstocks rubber (unknown clone), sustained in the nursery suspended for PET. At 30, 45, 60, 75 and 90 days after application, were evaluated: stalk diameter, plants height, number of leaflets and color index. At 100th day, the final evaluation was carried out measuring the dry weight, foliar area and physiological indices. The dose of 140 $\mathrm{mg}$ plant $^{-1}$ fertigation is the most appropriate for the production of rootstocks nursery suspended. However, the full potential of plant growth was not achieved with the doses tested. To obtain satisfactory results is recommended to use high quality rubber rootstock seeds.

Keywords: Hevea brasiliensis; seedling production; nutrient solution.

\section{INTRODUÇÃO}

Nativa do Brasil, a seringueira (Hevea brasiliensis Muell. Arg.) se destaca comercialmente na biossíntese de borracha, pois, após atingir sua maturidade fisiológica, a excisão de uma pequena parte do caule, conhecida como sangria, resulta na liberação do conteúdo citoplas mático, que contém grande quantidade de látex (LIU et al. 2015).

O láte x extraído da seringueira é a principal matéria-prima utilizada para a produção de borracha natural. No período de 1951 a 2005, os maiores produtores foram Tailândia, Indonésia e Malásia (UMAR et al. 2011). No Brasil, a demanda por borracha natural vem aumentando, e o segmento produtivo não consegue atender em quantidade suficiente as indústrias consumidoras, havendo a necessidade de se expandir a heveicultura no país.

FLOREST A, Curitiba, PR, v. 46, n. 1, p. 1 - 9, jan. / mar. 2016.

Barreto, R. F. et al.

ISSN eletrônico 1982-4688

DOI: $10.5380 /$ rf.v46il 33885 
Pilau et al. (2007) verificaram que as regiões Centro-Oeste e Sudeste do Brasil apresentam boas condições para ampliação da heveicultura, com características ideais ao seu desenvolvimento, porque apresentam baixos riscos da ocorrência do mal-das-folhas, doença causada pelo fungo Microcyclus ulei (P.Henn) v. Arx, considerada fator limitante na implantação de seringais (HORA JÚNIOR et al., 2013).

A heveicultura está crescendo no estado de Mato Grosso do Sul, em especial no município de Cassilândia, onde se encontra o maior plantio irrigado de seringueira do Brasil. Como consequência, tem-se o aumento da demanda por mudas e necessidade de experimentação vis ando melhorias no sistema de produção.

De forma convencional, os viveiros para produção de mudas de seringueira são instalados ao nível do solo, pois o método apresenta baixo custo e proporciona um bom crescimento das plantas. Entretanto, existe o risco da contaminação do substrato em que as plantas se desenvolvem por patógenos de solo e sementes de plantas daninhas, que podem ser disseminados para outras áreas após a fase de viveiro.

Devido aos problemas relacionados com a produção de mudas de seringueira diretamente no solo, a utilização de viveiro suspenso e substrato inerte visa garantir a qualidade fitossanitária das plantas, atendendo à Instrução Normativa ${ }^{\circ} 29$ do Ministério da Agricultura, Pecuária e Abastecimento (MAPA), de agosto de 2009 (BRASIL, 2009).

Sobre a adubação em porta-enxertos de seringueira, Zamunér Filho et al. (2012a) afirmam que a aplicação de 6 gramas por litro de adubo de liberação lenta é suficiente para que porta-en xertos do clone GT1 estejam aptos a enxertia aos 8 meses após a emergência, em recipientes com capacidade de 2 litros.

Nesse sentido, ao avaliarem sete clones de seringueira sobre porta-enxertos de mudas sortidas e portaenxertos de mudas monoclonais, Gireesh et al. (2012) não observaram evidência para sugerir que o crescimento e rendimento de clones foi significativamente influenciado pelo tipo de porta-enxerto, aos 12 anos após o início da extração do látex. Contudo, Arantes et al. (2010) afirmam que sementes de origem desconhecida, que possam ter sido coletadas em jardins monoclonais, podem originar plantas com baixo vigor.

Uma técnica bastante usada na produção de mudas é a fertirrigação, pois garante um melhor desenvolvimento das plantas, conforme observado por Zambrosi et al. (2012) na produção de porta-enxertos de citros. Já para a produção de porta-enxertos de seringueira em viveiro suspenso, são desconhecidas informações científicas sobre as concentrações ideais do formulado N, P e K, de aplicação prática e simples em solução nutritiva, que proporcione um crescimento satisfatório das plantas.

Pesquisas sobre o tema são necessárias, pois, com a aplicação de N, P e K via fertirrigação, pode-se acelerar o crescimento das plantas e reduzir o tempo para que os porta-enxertos de clone desconhecido estejam aptos a enxertia.

Diante do exposto, neste trabalho objetivou-se determinar a dosagem de N, P e K via fertirrigação mais adequada para a produção de porta-enxertos de seringueira em viveiro suspenso e verificar a influência do fornecimento desses nutrientes sobre o crescimento das plantas.

\section{MATERIAL E MÉTODOS}

O experimento foi desenvolvido na Universidade Estadual de Mato Grosso do Sul (UEMS), Unidade de

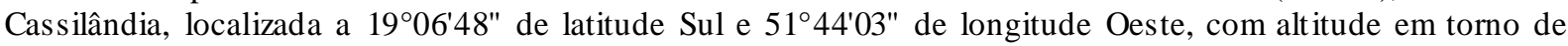
470 metros, em viveiro sus penso a céu aberto, no período de outubro de 2012 a janeiro de 2013. De acordo com a classificação climática de Köppen, a região apresenta clima tropical chuvoso (AW), com verão chuvoso e inverno seco. A precipitação pluviométrica acumulada nos meses de outubro, novembro e deze mbro de 2012 e janeiro de 2013 foi de 29, 256, 229 e $309 \mathrm{~mm}$, respectivamente. No mes mo período, a média da temperatura máxima foi de $35,7^{\circ} \mathrm{C}$, enquanto que a média da temperatura mínima foi de $22,5^{\circ} \mathrm{C}$. Os dados climáticos foram obtidos de uma estação meteorológica instalada próximo ao local do experimento.

Antes do início do experimento, os porta-enxertos de clone desconhecido estavam em sacolas plásticas de 10 × $20 \mathrm{~cm}$, com capacidade para 1,5 L. O substrato foi constituído por casca de pínus e vermiculita, que apresentava granulometria de $6,0 \mathrm{~mm}$, densidade de $275,9 \mathrm{~kg} . \mathrm{m}^{-3}$ e capacidade de retenção de água de $1,32 \mathrm{~kg} \cdot \mathrm{kg}^{-1}$ do substrato. A partir da análise química do substrato, foram identificados os teores de macronutrientes, em g. $\mathrm{kg}^{-1}: \mathrm{N}(4,70), \mathrm{P}(0,30), \mathrm{K}(0,50), \mathrm{Ca}(4,60), \mathrm{Mg}(0,60), \mathrm{S}(1,10)$; e de mic ronutrientes, em $\mathrm{mg} \cdot \mathrm{kg}^{-1}$ : B (24,0), Cu (15), Fe (5700), Mn (128), Zn (49).

O substrato recebeu $5 \mathrm{~g}$ de Osmocote ${ }^{\circledR}$, com liberação prevista para 9 meses dos seguintes elementos: $\mathrm{N}(15 \%), \mathrm{P}_{2} \mathrm{O}_{5}(9 \%), \mathrm{K}_{2} \mathrm{O}(12 \%), \mathrm{Mg}(1 \%), \mathrm{S}(2,3 \%), \mathrm{B}(0,02 \%), \mathrm{Cu}(0,05 \%), \mathrm{Fe}(1 \%), \mathrm{Mn}(0,06 \%), \mathrm{Mo}$ $(0,02 \%)$ e $\mathrm{Zn}(0,05 \%)$.

Com 7 meses após a emergência, cada porta-enxerto foi colocado em uma garrafa de polietileno tereftalato (PET), que foi levada ao viveiro suspenso, construído basicamente com postes de madeira e arame liso, sustentando a base das garrafas a $1,5 \mathrm{~m}$ de altura. 
O delineamento experimental utilizado foi em blocos ao acaso, com 5 tratamentos, 4 repetições e 10 plantas por parcela. Os tratamentos foram constituídos por 5 doses do fertilizante Nutrijá ${ }^{\circledR}(0,35,70,105$ e $140 \mathrm{mg}$.planta ${ }^{-1}$. emana $^{-1}$ ). O fertilizante era composto por nitrogênio (N), fósforo (P) e potássio (K) (19-19-19). As aplicações foram realizadas via fertirrigação, durante os meses de outubro de 2012 a janeiro de 2013.

Por ocasião da aplicação, as doses do fertilizante foram diluídas em água, sendo aplicados $112 \mathrm{ml}$ por planta, uma vez por semana. Essa quantidade de solução nutritiva visava atingir a capacidade de campo do substrato, que foi determinada pelo método do tubo de policloreto de vinil (PVC), seguindo a metodologia de Costa et al. (1997). Essa mesma quantidade de água foi aplicada diariamente, para irrigar cada um dos porta-enxertos.

Realizaram-se avaliações de 6 plantas de cada parcela aos 30, 45, 60, 75 e 90 dias após a aplicação dos tratamentos (DAT), dos parâmetros diâmetro do caule, altura de plantas, número de folíolos e índice de cor verde dos folíolos. O diâmetro do caule foi medido com paquímetro digital graduado em $\mathrm{mm}$, a $5 \mathrm{~cm}$ do colo da planta. Mediu-se a altura de planta, do colo ao ápice da mesma, com au xílio de uma trena graduada em cm. Contou-se o número de folíolos da planta, e o índice de cor verde foi medido em 1 folíolo de cada planta, na parte mediana da planta e da folha, com auxílio do aparelho CCM-200 (Chlorophyll Content Meter), sendo os valores dados em CCI. área foliar.

Fez-se uma avaliação final de 6 plantas por parcela aos 100 DAA, sendo mensuradas a massa seca e a

Para a determinação da massa seca dos folíolos, da massa seca da raiz e da massa seca total, as plantas foram separadas em raiz, caule e folíolos, sendo as raízes lavadas em água corrente. Após a separação, os materiais foram colocadas em sacos de papel e levados a estufa de circulação de ar forçada, a u ma temperatura de $70-75^{\circ} \mathrm{C}$, até at ingir peso constante. Por fim, foram verificadas as mass as em balança digital de precisão.

Em conjunto com a análise de massa seca dos folíolos, foram recortados $10 \mathrm{~cm}^{2}$ de 2 folhas de cada planta, com au xílio de u ma régua graduada em centímetros e estilete, sendo que, após a secagem e aferição da massa dos folíolos e dos $10 \mathrm{~cm}^{2}$, foi determinada a área foliar das plantas que constituiriam os tratamentos. Os índices fisiológicos razão de área foliar (RAF), área foliar específica (AFE) e razão de massa foliar (RMF) foram determinados a partir da metodologia de Benincasa et al. (2003).

Os dados foram submetidos ao teste $\mathrm{F}$, e posteriormente as variáveis com efeito significativo foram ajustadas a um modelo de regressão, com significância mínima de 5\% para os parâmetros da equação. As análises estatísticas foram realizadas pelo programa computacional Sistema para Análise de Variância SISVAR (FERREIRA, 2003).

\section{RES ULTADOS E DISCUSSÃO}

Não houve diferença do diâmetro do caule nas épocas de avaliação em função das doses aplicadas, acentuando-se que, na última época de avaliação, as plantas estavam com 10 meses após a emergência, que correspondeu aos 90 DAT (Tabela 1). Os valores observados neste ensaio foram próximos aos de Gonçalves et al. (2010) estudando fontes de fósforo no crescimento de porta-enxerto de seringueira sob condições de viveiro, com médias entre 6,12 e 7,85 mm.

Tabela 1. Diâmetro do caule de porta-enxertos de seringueira aos 30, 45, 60, 75 e 90 DAT em função das doses de N, P e K. Cassilândia, MS, 2012/2013.

Table 1. Stalk diameter of rootstocks rubber tree at 30, 45, 60, 75 DAT as a function of the doses of N, P and K. Cassilândia, MS, 2012/2013.

\begin{tabular}{|c|c|c|c|c|c|}
\hline \multirow{2}{*}{ Tratamento } & \multicolumn{5}{|c|}{ Época de avaliação } \\
\hline & $30 \mathrm{DAT}$ & $45 \mathrm{DAT}$ & $60 \mathrm{DAT}$ & $75 \mathrm{DAT}$ & $90 \mathrm{DAT}$ \\
\hline 0 & 5,50 & 5,85 & 5,91 & 5,98 & 6,09 \\
\hline 35 & 5,58 & 5,87 & 6,08 & 6,23 & 6,43 \\
\hline 70 & 5,52 & 6,28 & 6,34 & 6,56 & 6,67 \\
\hline 105 & 5,93 & 6,35 & 6,66 & 6,81 & 7,07 \\
\hline 140 & 5,32 & 5,88 & 6,22 & 6,38 & 6,58 \\
\hline Teste F & $1,86^{\mathrm{ns}}$ & $1,74^{\mathrm{ns}}$ & $1,67^{\mathrm{ns}}$ & $1,89^{\mathrm{ns}}$ & $2,55^{\mathrm{ns}}$ \\
\hline C. V. (\%) & 5,89 & 6,23 & 7,04 & 7,13 & 6,80 \\
\hline Regressão & - & - & - & - & - \\
\hline $\mathrm{R}^{2}$ & - & - & - & - & - \\
\hline
\end{tabular}

= não significativo. 
As doses de N, P e K utilizadas não incrementaram significativamente o diâmetro do caule (Tabela 1) para que atingissem $12 \mathrm{~mm}$ aos 10 meses (90 DAT), sendo este o diâmetro do caule a $5 \mathrm{~cm}$ do coleto estabelecido pela Instrução Normativa no 29 do Ministério da Agricultura, Pecuária e Abastecimento para que o porta-enxerto esteja apto a en xertia (BRASIL, 2009).

Provavelmente, o insucesso na obtenção do diâmetro mínimo do caule exigido para a enxertia deve-se à baixa qualidade das sementes. Como as sementes utilizadas no experimento eram de origem desconhecida, elas podem ter sido coletadas de jardins monoclonais. Segundo Arantes et al. (2010), em jard ins monoclonais a autopolinização é frequente, sendo que as sementes resultantes desse processo dão origem a plantas endogâmicas combaixo vigor.

Já Zamunér Filho et al. (2012a) obtiveram 99\% de porta-enxertos de seringueira (clone GT1) aptas à enxertia aos 8 meses de idade com a utilização de 6 gramas por litro de adubo de liberação lenta (fórmula 15-0912), em recipientes com capacidade de 2 litros. Os autores adicionaram 0,3 litro de substrato com a respectiva dose de adubo às parcelas dos tratamentos, para completar o volume, após o quarto lançamento foliar das plantas. Nesse sentido, Cardinal et al. (2007) apontaram o porta-en xerto GT 1 co mo recomendado para o estado de São Paulo, por apresentar bom rendimento produtivo.

Nota-se que a altura de plantas apresentou resposta linear aos 75 e 90 DAT (Tabela 2). Resposta semelhante à obtida por Cruz et al. (2011), que estudaram resposta de macronutrientes em mudas de fedegoso cultivadas em cas a de vegetação, tendo Argissolo Vermelho-Amarelo co mo substrato, notando, de maneira geral, o aumento da altura de plantas em função do fornecimento de doses crescentes de $\mathrm{N}, \mathrm{P}$ e $\mathrm{K}$, com efeito mais evidente para o P.

Tabela 2. Altura de porta enxertos de seringueira aos 30, 45, 60, 75 e 90 DAT em função das doses de N, P e K. Cassilândia, MS, 2012/2013.

Table 2. Height rootstocks rubber tree at 30, 45, 60, 75 and 90 DAT as a function of the doses of N, P and K. Cassilândia, MS, 2012/2013.

\begin{tabular}{|c|c|c|c|c|c|}
\hline \multirow{3}{*}{ Tratamento } & \multicolumn{5}{|c|}{ Época de avaliação } \\
\hline & $30 \mathrm{DAT}$ & $45 \mathrm{DAT}$ & $60 \mathrm{DAT}$ & $75 \mathrm{DAT}$ & $90 \mathrm{DAT}$ \\
\hline & $\cdots$ & & 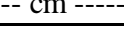 & & \\
\hline 0 & 47,85 & 49,37 & 49,78 & 50,34 & 50,86 \\
\hline 35 & 49,21 & 50,24 & 53,96 & 54,21 & 54,44 \\
\hline 70 & 49,96 & 50,90 & 53,17 & 55,65 & 56,76 \\
\hline 105 & 52,77 & 55,63 & 57,91 & 58,58 & 60,44 \\
\hline 140 & 50,21 & 53,05 & 57,59 & 57,63 & 58,29 \\
\hline Teste F & $1,08^{\mathrm{ns}}$ & $2,80^{\mathrm{ns}}$ & $3,20^{\mathrm{ns}}$ & $6,24^{* *}$ & $4,61^{*}$ \\
\hline C. V. $(\%)$ & 6,93 & 5,80 & 6,92 & 4,70 & 6,11 \\
\hline Regressão & - & - & - & $\mathrm{L}^{* *}$ & $\mathrm{~L}^{* *}$ \\
\hline $\mathrm{R}^{2}$ & - & - & - & 0,85 & 0,81 \\
\hline
\end{tabular}

= significativo a $5 \% ; "=$ significativo a $1 \% ;{ }^{\mathrm{ns}}=$ não significativo; $\mathrm{L}=$ ajuste linear.

Os dados do presente ensaio (Tabela 2) ficaram abaixo do valor de altura de plantas $(66,30 \mathrm{~cm})$ obtido por Rodrigues e Costa (2009) ao analisarem diferentes substratos em mudas de seringueira, porém aos 15 meses após a emergência das plântulas, ou seja, com 5 meses a mais de crescimento, em tubetes com capacidade para 2,8 litros e transplantadas aos 12 meses para vasos de 7 litros. Assim, o maior período de condução do experimento e maior volu me de substrato proporcionaram o resultado superior.

Com relação ao número de folíolos dos porta-enxertos, a partir dos 45 DAT, observou-se um aumento linear, de acordo com a elevação das doses dentro de cada época de avaliação (Tabela 3 ).

Ao estudar o crescimento de porta-enxertos de seringueira em função da idade em condições de campo, Oliveira (2006) observou que o número de folhas aumentou de acordo com o crescimento das plantas, se ndo que o maior incremento ocorreu entre o oitavo e o décimo mês após a emergência das plantas, ao contrário do observado no presente trabalho, em que ocorreu a redução do número de folíolos entre os 30 e 90 DAT (Tabela 3), ou seja, entre o oitavo e o décimo mês após a emergência.

Dessa forma, até os 30 DAT, o Osmocote ${ }^{\circledR}$ que foi aplicado no substrato era suficiente para atender a demanda nutricional do número de folíolos das plantas, sendo que, após esse período, havia a necessidade de fornecer maiores concentrações de nutrientes aos porta-enxertos. A maior necessidade de nutrientes nesse período também foi observado por Oliveira (2006), que, estudando o teor e acúmulo de macronutrientes em porta-enxertos de seringueira em função da idade em condições de campo, concluiu que o período em que as plantas mais absorvem nutrientes é entre o oitavo e o décimo mês. 
Tabela 3. Número de folíolos de porta-enxertos de seringueira aos 30, 45, 60, 75 e 90 DAT em função de doses de N, P e K. Cassilândia, MS, 2012/2013.

Table 3. Nu mber of leaflets rootstocks rubber tree at 30, 45, 60, 75 and 90 DAT as a function of the doses of N, P and K. Cassilândia, MS, 2012/2013.

\begin{tabular}{llllll}
\hline \multicolumn{1}{c}{ Tratamento } & \multicolumn{5}{c}{ Epoca de avaliação } \\
\cline { 2 - 6 } \multicolumn{1}{c}{----- mg ----- } & 30 DAT & 45 DAT & 60 DAT & 75 DAT & 90 DAT \\
\hline 0 & 17,00 & 13,50 & 13,79 & 11,66 & 8,21 \\
35 & 17,16 & 15,67 & 14,46 & 13,29 & 11,83 \\
70 & 20,83 & 17,79 & 20,16 & 17,45 & 14,37 \\
105 & 25,45 & 22,25 & 23,96 & 21,71 & 15,62 \\
140 & 22,87 & 24,29 & 26,42 & 22,12 & 15,96 \\
Teste F & $3,21^{\text {ns }}$ & $4,65^{*}$ & $28,62^{* *}$ & $14,92^{* *}$ & $7,28^{* * *}$ \\
C. V. $(\%)$ & 19,75 & 22,31 & 10,61 & 14,28 & 18,12 \\
Regressão & - & $\mathrm{L}^{* *}$ & $\mathrm{~L}^{* *}$ & $\mathrm{~L}^{* *}$ & $\mathrm{~L}^{* *}$ \\
$\mathrm{R}^{2}$ & - & 0,98 & 0,95 & 0,95 & 0,89 \\
\hline
\end{tabular}

= significativo a $5 \% ; "=$ significativo a $1 \% ;{ }^{\text {ns }}=$ não significativo $; \mathrm{L}=$ ajuste linear.

Houve aumento do índice de cor verde dos folíolos conforme a elevação das doses de N, P e K aos 45, 60, 75 e 90 DAT (Tabela 4). O aumento da intensidade da coloração dos folíolos deve-se à relação entre a quantidade de clorofila e o teor de nitrogênio na planta, sendo es se índice adequado para avaliar as variações nos teores de nitrogênio em várias culturas, incluindo a batata (MAROUANI et al., 2015).

Tabela 4. Índice de cor verde de porta-en xertos de seringueira aos 30, 45, 60, 75 e 90 DAT em função das doses de N, P e K. Cassilândia, MS, 2012/2013.

Table 4. Color index rootstock rubber tree at 30,45, 60, 75 and 90 DAT as a function of the doses of N, P and K. Cas silândia, MS, 2012/2013.

\begin{tabular}{|c|c|c|c|c|c|}
\hline \multirow{2}{*}{ Tratamento } & \multicolumn{5}{|c|}{ Época de avaliação } \\
\hline & $30 \mathrm{DAT}$ & $45 \mathrm{DAT}$ & $60 \mathrm{DAT}$ & $75 \mathrm{DAT}$ & $90 \mathrm{DAT}$ \\
\hline ------- mg ------ & & 1 & --- CC & ----------. & -------- \\
\hline 0 & 8,27 & 5,20 & 1,17 & 3,64 & 4,83 \\
\hline 35 & 8,72 & 6,08 & 1,74 & 5,27 & 8,01 \\
\hline 70 & 10,25 & 8,08 & 2,52 & 6,05 & 11,99 \\
\hline 105 & 12,29 & 10,01 & 3,08 & 7,13 & 17,17 \\
\hline 140 & 11,12 & 9,31 & 3,69 & 8,53 & 18,40 \\
\hline Teste F & $2,10^{\mathrm{ns}}$ & $8,51^{* *}$ & $19,51^{* *}$ & $7,65^{* *}$ & $11,59^{* *}$ \\
\hline C. V. $(\%)$ & 22,65 & 18,25 & 18,59 & 21,83 & 28,24 \\
\hline Regressão & - & $\mathrm{L}^{* * *}$ & $\mathrm{~L}^{* *}$ & $\mathrm{~L}^{* * *}$ & $\mathrm{~L}^{* *}$ \\
\hline $\mathrm{R}^{2}$ & - & 0,87 & 0,99 & 0,98 & 0,97 \\
\hline
\end{tabular}

= significativo a $1 \% ;{ }^{\mathrm{ns}}=$ não significativo; $\mathrm{L}=$ ajuste linear.

Como as médias de intensidade de cor verde ajustaram-se ao modelo linear, tal comportamento indica que maiores concentrações de nitrogênio devem ser testadas, uma vez que a planta apresenta um valor máximo de incorporação de clorofila (comportamento quadrático). Não foram encontrados trabalhos na literatura com índice de cor verde em porta-en xertos de seringueira, entretanto, resultados com comportamento quadrático em função de doses de nitrogênio foram constatados em outras culturas, como feijão (SANT'A NA et al., 2010).

Nota-se o mes mo comportamento do índice de cor verde para a seca dos folíolos e área foliar (Figura 1). Assim, não foi observado, dentro do intervado de doses testadas, o ponto máximo desses parâmetros, que são utilizado para verificar o potencial fotossintetizante de uma planta. 


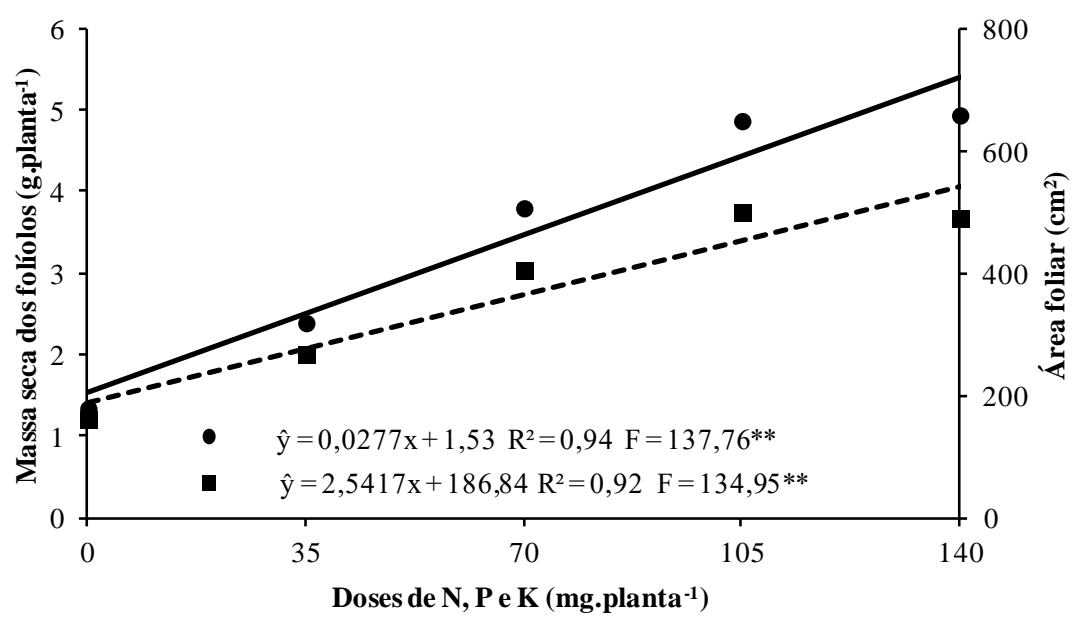

Figura 1. Massa seca dos folíolos (•) e área foliar (ロ) de porta-en xertos de seringueira em função de doses de N, P e K. Cas silândia, MS, 2013.

Figure 1. Dry material of leaflets $(\bullet)$ and leaf area $(\boldsymbol{\bullet})$ rootstocks rubber tree as a function of $\mathrm{N}, \mathrm{P}$ and $\mathrm{K}$. Cassilândia, MS, 2013.

Ao verificar o efeito da adubação no crescimento do porta-enxerto de limoeiro-cravo em tubete, utilizando substrato à base de casca de pínus e vermiculita, Ro zane et al. (2009) ta mbém constataram au mento da área foliar com a ap licação de N, P e K.

Os valores da massa seca dos folíolos (Figura 1) que ficaram entre 1,34 e 4,98g.planta ${ }^{-1}$ foram inferiores aos observados por Viégas et al. (1992), que estudaram a absorção de macro e micronutrientes de porta-enxertos de seringueira até os 240 dias e obtiveram 8 a 10 g.planta ${ }^{-1}$, em casa de vegetação e utilizando vasos para 4 litros, em Piracicaba, SP.

A área foliar específica, obtida pela razão entre a área foliar e a massa seca dos folíolos, apresentou comportamento linear negativo, em função do aumento das doses de N, P e K (Figura 2), indicando que a taxa de expansão dos folío los não acompanha o aumento em espessura. Para clones adultos de seringueira, Conforto et al. (2011) notaram aumento da área foliar específica somente quando submeteu as folhas a sombreamento, pois, nessas condições, o investimento é maior na área foliar e menor em tecidos de sustentação, para aumentar o potencial fotossintético da planta.

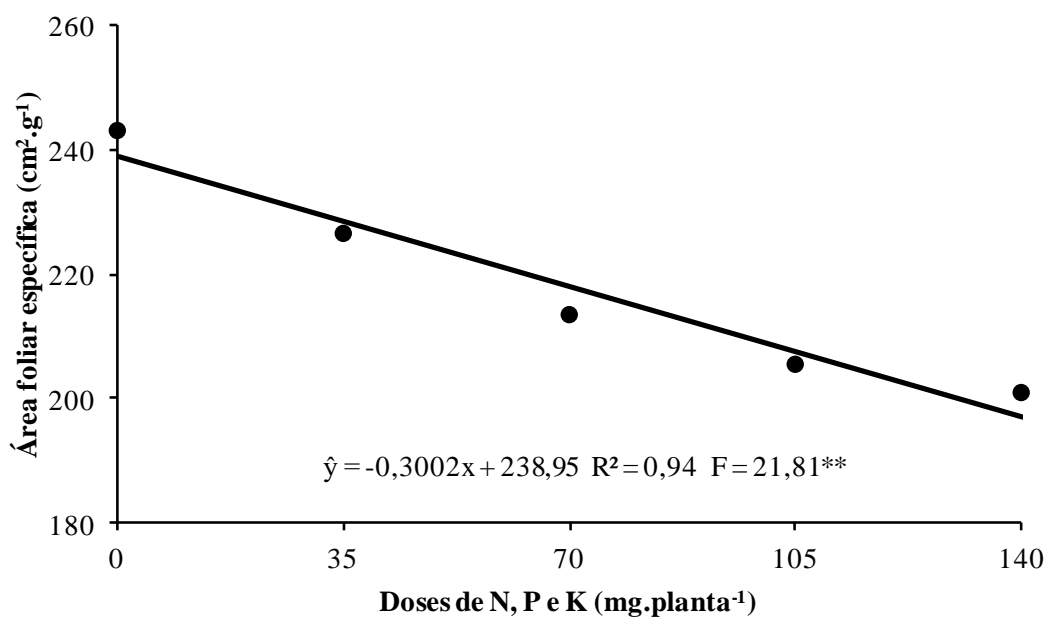

Figura 2. Área foliar específica de porta-en xertos de seringueira em função de doses de N, P e K. Cassilândia, MS, 2013.

Figure 2. Specific leaf area rootstocks rubber tree as a function of N, P and K. Cassilândia, MS, 2013. 
Mesmo com a queda na área foliar específica (Figura 2), a razão de área foliar, representada pela razão entre a área foliar e a massa seca total, ajustou-se a uma equação do primeiro grau (Figura 3), de modo que o aumento das dose de N, P e K incrementou a área foliar útil para a fotossíntese. A razão de massa foliar, que mostra a massa foliar em relação à massa total das plantas, apresentou o mesmo comportamento a razão de área foliar (Figura 3).

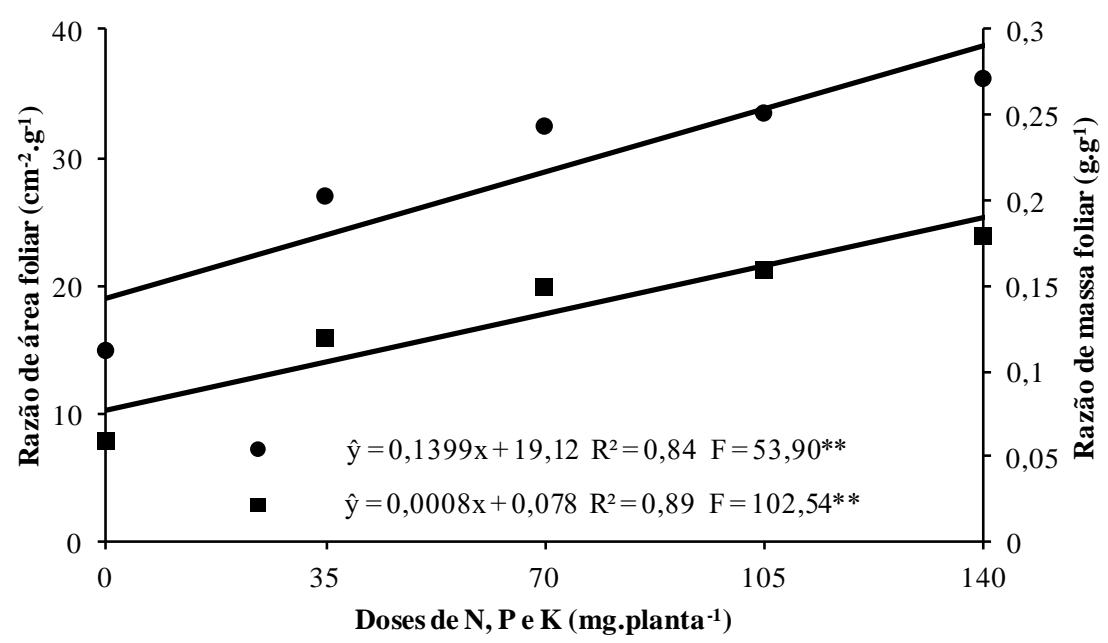

Figura 3. Razão de área foliar (•) e razão de massa foliar (•) de porta-enxertos de seringueira em função de doses de N, P e K. Cassilândia, MS, 2013.

Figure 3. Leaf area ratio $(\bullet)$ and leaf mass ratio ( $\bullet$ ) rootstocks rubber tree as a function of $\mathrm{N}, \mathrm{P}$ and $\mathrm{K}$. Cassilândia, MS, 2013.

A matéria seca total apresentou ajuste linear em função do aumento das doses aplicadas (Figura 4), sendo influenciada principalmente pela matéria seca dos folíolos, pois, quando analisadas separadamente, a matéria seca da raíz e a do caule não apresentaram dife rença significativa.

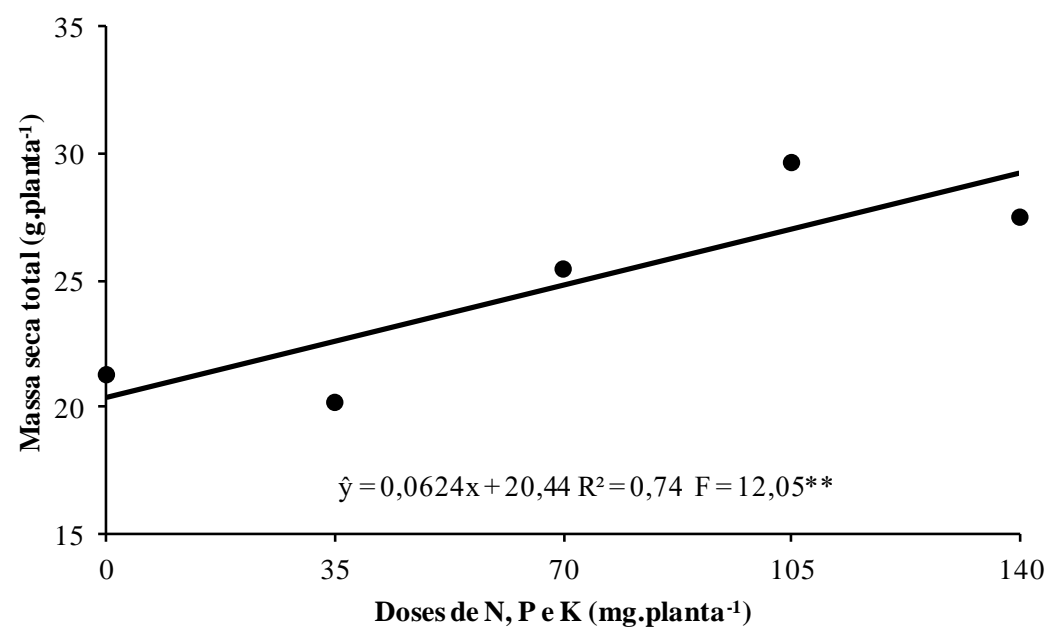

Figura 4. Matéria seca total de porta-enxertos de seringueira em função de doses de N, P e K. Cassilândia, MS, 2013.

Figure 4. Dry matter rootstocks rubber tree as a function of N, P and K. Cas silândia, MS, 2013.

Sobre a matéria seca das raízes, é provável que o tamanho do recipiente $(10$ x $20 \mathrm{~cm})$, com capacidade para $1,5 \mathrm{~L}$ de substrato, tenha restringido o desenvolvimento do sistema radicular e por isso não tenha apresentado efeito significativo. O mesmo comportamento foi observado por Rozane et al. (2009), que estudaram o efeito da adubação no crescimento do porta-enxerto de limoeiro-cravo em tubetes $(2,8 \times 12,3)$ com capacidade para $75 \mathrm{~mL}$ de substrato e não constataram alteração da matéria seca das raízes sobre adubação com

FLOREST A, Curitiba, PR, v. 46, n. 1, p. 1 - 9, jan. / mar. 2016. 
N, P e K. Contudo, Zamunér Filho et al. (2012b) concluíram ser viável a utilização de recipientes com volu me a partir de 1,5 L para a produção de porta-enxertos clonais GT1 de seringueira, pois, aos 8 meses de idade das plantas, o diâmetro do caule não diferiu entre recipientes com volu mes entre 1,5 e 2,7 L.

Mesmo a seringueira sendo nativa da Floresta Amazônica, região com diversos tipos de solo, em que vários deles são de baixa fertilidade natural (VALE JÚNIOR et al., 2011), estudos para a recomendação de fertilizantes vêm sendo realizados (CHEN et al., 2011), pois as plantas apresentam resposta, como visto no presente trabalho. Contudo, os resultados do diâmetro do caule, sendo um dos parâmetros mais relevantes para a produção de porta-enxertos de seringueira, foram insatisfatórios. O baixo vigor das plantas endogâmicas pode ter contribuído para o resultado insatisfatório do diâmetro do caule, resultado que poderia ter sido diferente se tivessem sido usadas sementes certificadas.

\section{CONCLUS ÕES}

- Nas condições deste experimento, a dose de $140 \mathrm{mg}$ de N, P e K por planta via fertirrigação é a mais adequada para a produção de porta-enxertos em viveiro suspenso.

- Estudos com o uso de maiores dosagens de N, P e K aplicados via fertirrigação na produção de portaenxertos de seringueira em viveiro suspenso são necessários, visto que neste trabalho o potencial máximo de crescimento das plantas não foi atingido com as doses testadas.

- Para a obtenção de resultados satisfatórios, é recomendado o uso de sementes de porta-enxertos de seringueira de alta qualidade.

\section{REFERÊNCIAS}

ARANTES; F. C.; GONÇALVES, P. S.; SCALOPPI JÚNIOR, E. J.; MORAES, M. L. T.; RESENDE, M. D. V. Ganho genético com base no tamanho efetivo populacional de progênies de seringueira. Pesquisa Agropecuária Brasileira, Brasília, v. 45, p. 1419 - 1424, 2010.

BENINCASA, M. M. P. Análise de crescimento de plantas: noções básicas. , 2 ed. Jaboticabal: FUNEP, 2003. $41 \mathrm{p}$.

BRASIL. Instrução Normativa n. 29, de 5 de agosto de 2009. Institui os padrões de identidade e qualidade de sementes de seringueira. Diário Oficial da União, Brasília, DF, 6 ago. 2009. Disponível em: <http://www.ciflorestas.com.br/arquivos/doc_normas_seringueira_26735.pdf>. Acesso em: 16 jun. 2013.

CARDINAL, A. B. B.; GONÇALVES, P. S.; MARTINS, A. L. M. Influência de seis porta-enxertos sobre a produção de clones superiores de seringueira. Bragantia, Campinas, v. 66, p. 277 - 284, 2007.

CHEN, B.; CAO, J.; WANG, J.; WU, Z.; XIE, G. Development and Implementation of Site-Specific Fertilizer Recommendation Model Based on Nutrient Balance for Rubber Plantation. Agronomy Journal, Madison, v. 103,p. $464-471,2011$.

CONFORTO, E. C.; BITTENCOURT JÚNIOR, N. S.; SCAlOPPI JÚNiOR, E. J.; MORENO, R. M. B. Comparação entre folhas sombreadas de sete clones adultos de seringueira. Ceres, Viçosa, v. 58, p. 29 - 34 , 2011.

COSTA, A. C. S.; NANNI, M. R.; JESKE, E. Determinação da umidade na capacidade de campo e ponto de murchamento permanente por diferentes metodologias. Uni mar, Maringá, v. 19, p. 827 - 844, 1997.

CRUZ, C. A. F.; PAIVA, H. N.; CUNHA, A. C. M. C. M.; NEVES, J. C. L. Resposta de mudas de Senna macranthera cultivadas em Arg issolo Vermelho-A marelo a macronutrientes. Ciência Florestal, Santa Maria, v. 21, p. 63 - 76, 2011.

FERREIRA, D. F. Sis var versão 4.2. DEX/UFLA, Lavras/MG. 2003.

GIREESH, T.; VARGHESE, Y. A.; WOESTE, K. E.; MERCYKUTTY, V. C.; MARATTUKALAM, J. G. Effect of monoclonal and assorted seedling rootstocks on long term growth and yield of Hevea clones. Silvae Genetica, Joensuu, v. 61, p. 52 - 57, 2012.

GONÇALVES, E. C. P.; PRADO, R. M.; CORREIA, M. A. R. Fontes de fósforo no crescimento de portaenxerto de seringueira sob condições de viveiro. Floresta, Curitiba, v. 40, p. 813 - 818, 2010. 
HORA JÚNIOR, B. T.; MAFFIA, L. A.; MIZUBUTI, E. S. G. Population biology of Microcyclus ulei, the causal agent of South American leaf blight of rubber trees in Latin America. Phytopathology, Austin, v. 103, p. $61-62,2013$.

LIU, S.; LAN, J.; ZHOU, B.; QIN, Y.; ZHOU, Y.; XIAO, X.; YANG, J.; GOU, J.; QI, J.; HUANG, Y.; TANG, C. HbNIN2, a cytosolic alkaline/neutral-invertase, is responsible for sucrose catabolism in rubber-producing laticifers of Hevea brasiliensis (para rubber tree). New Phytologist, Lancaster, v. 206, p. 709 - 725, 2015.

MAROUANI, A.; BEHI, O.; SALAH, H. B.; QUILEZ, O. A. Establishment of Chlorophyll Meter Measurements to Manage Crop Nitrogen Status in Potato Crop. Communications in soil science and plant analysis, New York, v. 46, p. 476 - 489, 2015.

OLIVEIRA, J. P. Crescimento e nutrição mineral de porta-enxer tos de seringueira (Hevea spp.) em função da i dade. 77 f. Dis sertação (Mestrado em Agronomia) - Universidade Federal Rural da A mazônia, Be lém, 2006.

PILAU, F. G.; MARIN, F. R.; ASSAD, E. D.; PINTO, H. S.; BARBARISI, B. F. Zoneamento agroclimático da heveicultura para as regiões Centro-Oeste e Sudeste do Brasil. Revista Brasileira de Agrometeorologia, Piracicaba, v. 15, p. 161 - 168. 2007.

RODRIGUES, V. A.; COSTA, P. N. Análise de diferentes substratos no crescimento de mudas de seringueira. Re vista científica eletrônica de Engenharia Florestal, Botucatu, v. 16, p. 8 - 17, 2009.

ROZANE, D. E.; PRADO, R. M.; NATALE, W.; BEUTLER, A. N.; SILVA, S. R.; BARBOSA, J. C. Efeito das doses de nitrogênio, fósforo e potássio na nutrição e na produção do porta-enxerto de limoeiro-cravo. Acta Scientiarum, Maringá, v. 31, p. 255 - 260, 2009.

SANT'ANA, E. V. P.; SANTOS, A. B.; SILVEIRA, P. M. Adubação nitrogenada na produtividade, leitura SPAD e teor de nitrogênio em folhas de feijoeiro. Pesquisa Agropecuária Tropical, Goiânia, v. 40, p. 491 496, 2010

UMAR, H. Y.; GIROH, D. Y.; AGBONKPOLOR, N. B.; MESIKE, C. S. An Overview of World Natural Rubber Production and Consumption: An Implication for Economic Empowerment and Poverty Alleviation in Nigeria. Journal of Human Ecology, New York, v. 33, p. 53 - 59, 2011.

VALE JÚNIOR, J. F.; SOUZA, M. I. L.; NASCIMENTO, P. P. R. R.; CRUZ, D. L. S. Solos da Amazônia: etnopedologia e desenvolvimento sustentável. Revista Agroambiente, Boa Vista, v. 5, p. 158 - 165, 2011.

VIÉGA S, I. J. M.; HAAG, H. P.; BUENO, N.; PEREIRA, J. P. Nutrição mineral de seringueira. XII. Absorção de macro e micronutrientes nos primeiros 240 dias. Scientia Agrícola, Piracicaba, v. 49, p. 41 - 52, 1992.

ZAMBrosi, F. C. B.; MATTOS JÚNIOR, D.; FURLANI, P. R.; QUAGGIO, J. A.; BOARETTO, R. M. Eficiência de absorção e utilização de fósforo em porta-enxertos cítricos. Revista Brasileira de Ciência do Solo, Viçosa, v. 36, p. 485 - 496, 2012.

ZAMUNÉR FILHO, A. N.; VENTURIN, N.; PEREIRA, A. V.; PEREIRA, E. B. C.; MACEDO, R. L. G. Doses of controlled-re lease fertilizer for production of rubber tree rootstocks. Cerne, Lavras, v. 18, p. 239 - 245, 2012 a.

ZAMUNÉR FILHO, A. N.; PEREIRA, A. V.; PEREIRA, E. B. C. Tamanho de recipientes para produção de mudas suspensas de seringueira. 2012b. Ministério da Agricultura, Pecuária e Abastecimento: Câmara Setorial da Borracha Natural. 21 $1^{\text {a }}$ Reunião Ordinária de 11/04/2012. Disponível em: <http://www.agricultura.gov.br /arq_editor/file/camaras_setoriais/Borracha_natural/21RO/Reuni\%C3\%A3o_de_Seringueira_DPD.pdf $>$. Acesso em: 10 maio 2015. 